\title{
A Framing Analisys de Goffman e sua aplicação nos estudos em Comunicação ${ }^{1}$
}

\author{
Luis Antonio Hangai ${ }^{2}$
}

GOFFMAN, Erving. Os quadros da experiência social: uma perspectiva de análise. Petrópolis: Editora Vozes. 2012.

Desenvolvida inicialmente por Erving Goffman, a perspectiva metodológica do enquadramento - mais conhecida como framing analysis - desencadeou uma série de mudanças no pensamento sociológico durante a segunda metade do século XX. Herdeiro do interacionismo simbólico, corrente intelectual inaugurada na Universidade de Chicago a partir dos anos de 1920, o pensador incide suas análises sobre o universo cotidiano, elevando-o a um novo patamar dentro das ciências sociais e humanas. Seus postulados influenciaram novas linhas de pesquisa em áreas diversas como a comunicação, mobilização social, arte e política. A sistematização das teorias acerca do enquadramento resultou em sua obra "Frame analysis: an essay on the organization of experience", de 1974, cuja versão traduzida para o português brasileiro, produzida pela Editora Vozes, chegou às livrarias somente em 2012 sob o título "Os quadros da experiência social: uma perspectiva de análise".

\section{Principais conceitos}

A ideia central desse livro é a de que a experiência de cada indivíduo resulta de como ele enquadra a realidade ao seu redor. A subjetividade e o conjunto de significados empregados para decifrar e compreender o mundo são os elementos construtores daquilo que é considerado real para cada pessoa. Enquadrados sempre a partir de uma perspectiva individual, os fatos e os eventos sobre os quais alguma consciência se dirige apenas são integrados à experiência de uma pessoa quando

\footnotetext{
1 Trabalho apresentado à terceira edição da Revista Ação Midiática - Estudos em Comunicação, Sociedade e Cultura, publicação ligada ao Programa de Pós-Graduação em Comunicação e Sociedade, da Universidade Federal do Paraná.

2 Jornalista, especialista em Novas Mídias e mestrando em Comunicação e Sociedade pela Universidade Federal do Paraná. Email: hangailuis@gmail.com
} 
interpretados e codificados como objetos de atenção. Goffman direciona suas reflexões para o quadro (frame), um amplo conceito que, ao se distanciar da realidade produzida por amplos sistemas sociais, aproxima-se do aspecto microscópico das interações interpessoais do cotidiano.

O quadro, portanto, é uma limitada estrutura cognitiva empregada subjetivamente pelo indivíduo a fim de que este possa atribuir significados aos objetos e aos acontecimentos físicos e abstratos que o cercam. Pode-se falar de um ponto de vista particular que delimita as atividades, enquadrando-as no espaço e no tempo enquanto delas se extrai algum sentido plausível que possa ser incorporado à experiência. $\mathrm{O}$ quadro, entretanto, não deve ser confundido com uma interpretação generalizada de vários indivíduos, mas sim como um esquema interpretativo único e pessoal que cada um aplica sobre uma determinada faixa de atividade. Trata-se, então, de uma capacidade subjetiva de ordenar as peças detectadas pela percepção e transformá-las em conjuntos significantes diante da consciência individual.

$\mathrm{O}$ ato de atribuir significado a algo que, de outra maneira, estaria desprovido de significação é chamado por Goffman de esquema primário. Uma atividade enquadrada da qual se possa extrair um sentido sem a necessidade de recorrer a outro enquadramento prévio é essencialmente primária por definição. Na vivência cotidiana e nas relações informais os esquemas primários são revelados a todo o momento: tornamse visíveis a cada vez que a consciência ativa significados para objetos e os enquadra em uma faixa de atividade sem que com isso seja preciso resgatar uma faixa de atividade antecedente.

Os esquemas primários ainda podem ser transformados - ou, como prefere Goffman, receberem novas laminações - de acordo com duas lógicas. A primeira delas é a tonalização, em que opera a adição de uma nova camada de significados sobre uma faixa de atividade preconcebida. Trata-se de reposicionar um acontecimento a partir de outro ângulo de percepção. Por exemplo, uma briga entre duas pessoas na rua pode ser enquadrada como um esquema primário. Mas se este conflito for, na verdade, um faz de conta, uma brincadeira ou um treinamento, então se adiciona ao esquema primário da luta uma nova rede significante que permite o reconhecimento da briga como não verdadeira, mas como simulação. Note-se que a nova laminação não destitui o esquema primário de sentido, mas apenas o envolve com outra camada de significados. O núcleo 
do quadro continua sendo o acontecimento em si (a briga e o que ela significa para as pessoas), mas sua borda situa a briga em outro contexto (a diversão ou o treinamento).

A segunda lógica de transformação do esquema primário é a maquinação, cujo propósito é induzir uma falsa convicção do que está realmente acontecendo. Esse mecanismo é geralmente empregado por aqueles que desejam produzir o engano e a trapaça, situando alguém no papel de “enredado", isto é, a vítima da armação. A ideia central do maquinador é manipular o enquadramento de algum indivíduo fazendo com que este não perceba a realidade, enredando-o em uma situação sob o controle dos maquinadores. Quando a farsa é descoberta e se descortina a trama, a faixa de atividade é reenquadrada e aquilo que antes era percebido como um esquema primário ou, no máximo, uma atividade tonalizada, passa a ser interpretado como efeito da maquinação.

Aquilo que determina o sentido de uma faixa de atividade, portanto, é o enquadramento produzido pelo indivíduo participante. No entanto, essa é uma dinâmica estritamente subjetiva. As coisas são reais de acordo com uma perspectiva adotada: a perspectiva daquele que acredita estar sendo observado e agindo sobre a realidade. Goffman afirma que esse quadro de percepção subjetiva está posicionado em um mundo fervilhante de acontecimentos laterais e simultâneos que se constituem como pistas paralelas à atividade enquadrada. Nesse sentido, aquele que enquadra algo como real deve ter consciência de que a realidade existe para além desse quadro e que é determinada por uma série incontável de eventos laterais à narrativa principal enquadrada. Por outro lado, o indivíduo é também capaz de desatender para todos esses eventos laterais com a finalidade de manter seu foco em um objeto específico sobre o qual recai todo seu enquadramento.

Um importante aspecto da análise de quadros salientado por Goffman é o de que toda atividade enquadrada encontra-se inevitavelmente ancorada em seu mundo circundante. A faixa de atividade sobre a qual o individuo dedica-se a enquadrar decorre de uma confluência de recursos materiais e sociais que possibilitam o seu próprio enquadramento. $\mathrm{O}$ correto quadro de um debate político precisa, primeiramente, que os candidatos envolvidos se desloquem para um determinado espaço a fim de que possam discutir suas propostas governamentais entre si. A borda do quadro refere-se, então, à fronteira imaginária que separa a faixa de atividade enquadrada do mundo ao seu redor, não se constituindo nem como parte do cenário nem como parte do mundo, mas 
reguladora de ambas. No caso exemplificado, os políticos referidos exercem seus papéis de candidatos durante o enquadramento do debate político, mas não abandonam a essência que trouxeram do mundo exterior, isto é, o seu "si mesmo" (self).

Os indivíduos, a partir do quadro por eles definido, exercem papéis de acordo com a atividade enquadrada. Postos em um debate político, eles interpretam papéis de candidatos públicos e suas ações serão guiadas segundo esse princípio. Estarão atentos ao tempo das perguntas e respostas, aguardarão os momentos para réplicas e tréplicas e, naturalmente, estarão focados em seduzir, com argumentos e enunciados espirituosos, os potenciais eleitores que os assistem. Enfim, os quadros requerem que seus participantes exerçam papéis estruturados pela faixa de atividade central e seu objetivo. Portanto, um papel pode ser resumido a uma faceta desempenhada pelo indivíduo com o propósito de se adequar à atividade enquadrada.

Goffman recorre a um conceito-chave do interacionismo simbólico para elucidar esta fórmula pessoa-papel anteriormente mencionada. $\mathrm{O}$ autor, assim como George $\mathrm{H}$. Mead, afirma que cada indivíduo é dotado de um eu (self), uma essência de personalidade que antecede a todos os papéis que ele venha a desempenhar. Este "eu" resulta da história biográfica do indivíduo e é sempre levado adiante, mesmo quando ele se deixa absorver por um papel social. A sua biologia e o seu estilo de agir e pensar são indissociáveis de seu ser, mesmo quando está desempenhando um papel. Com isso, Goffman se aproxima de uma sociologia cujo foco reside no indivíduo capaz de exercer múltiplos papéis, refutando, em contrapartida, a corrente intelectual que prioriza estruturas sociais e sua determinação na personalidade humana.

\section{Comunicação}

A intersecção entre análise de quadros e estudos sobre comunicação não é novidade. No campo da mídia, os enquadramentos começaram a ser estudados na década de 80, especialmente a partir dos trabalhos de Robert Entman (1989) e Gaye Tuchman (1993). Desde então foram difundidos novos métodos e técnicas para captar a essência dos quadros explorados pelos meios de comunicação, com especial atenção às notícias jornalísticas. Estas últimas, partindo-se da perspectiva do enquadramento, reconfiguraram-se como recortes subjetivos da realidade operados pelos jornalistas. 
Cada texto noticioso, portanto, não pode mais ser verificado como uma unidade do real, mas sim como uma construção simbólica promovida por agentes especializados em sua tentativa de enquadrar a realidade. Nesse sentido, as pesquisas fundamentadas na frame analysis debruçaram-se sobre como o jornalismo constrói seus enquadramentos acerca do mundo e quais recursos e medidas ele usa para isso.

A frame analysis incorporada aos estudos em jornalismo resultou na linha de pesquisa conhecida como framing. Além de identificar e analisar os elementos que compõem o quadro jornalístico, os estudiosos dessa área também demonstram uma notável preocupação em verificar os "quadros dominantes", isto é, os tipos de enquadramento interpretativo que mais abundam nos noticiários. Parte-se do pressuposto de que qualquer produção jornalística precisa recorrer a recursos externos para completar o seu quadro e posteriormente publicá-lo. Políticos, empresários e organizações sociais são fontes frequentemente recuperadas pelo jornalista em seu ofício de construir a reportagem. Consequentemente, os frames de tais entidades são absorvidos pelos noticiários e reapresentados ao público. A partir dessa concepção é possível revelar quais são os aspectos da realidade mais destacados, não somente pelos jornalistas, mas também por aqueles que encontram suas vozes amplificadas nos veículos de comunicação.

Para além do jornalismo, os postulados de Goffman também incidiram sobre a ideia de comunicação em âmbitos políticos. Uma aproximação notável nesse sentido é a de Snow e Benford (1988), que discorrem sobre como os atores coletivos inseridos no processo de mobilização social empregam quadros interpretativos da realidade, permitindo-lhes analisar sua situação atual e promover reivindicações públicas. Durante as interações, os sujeitos políticos aproximam seus enquadramentos, o que lhes serve de partida para o diagnóstico de problemas comuns. Posteriormente, quando um grupo se constitui, articulam-se estratégias e ações com base no enquadramento coletivo da realidade, delineando um fator com potencial de explicar o nascimento e o desenvolvimento de identidades políticas.

O quadro de Goffman assim se estabelece como um valioso dispositivo teórico e, especialmente, uma promissora via metodológica para a análise de comunicação midiática e também política. Embora a aplicação do conceito possa se adequar a diferentes campos de estudo, ele não perde a sua especificidade: explicar de que 
maneira o indivíduo constrói sua experiência pessoal com base no enquadramento aplicado sobre aquilo que ele julga ser real. Provocador, Goffman questiona mesmo se o que tomamos por real não passa de um ponto de vista.

\section{REFERÊNCIAS:}

GOFFMAN, Erving. Os quadros da experiência social: uma perspectiva de análise. Petrópolis: Editora Vozes. 2012.

ENTMAN, Robert M. Democracy without citizens: media and the decay or american politics. New York: Oxford University Press, 1989.

TUCHMAN, Gaye. Contando "estórias”. In: TRAQUINA, Nelson (org.), Jornalismo: questões, teorias e estórias. Lisboa: Veja. 1993.

SNOW, David, BENFORD, Robert. Ideology, Frame Resonance, and Participant Mobilization. In: International Social Movement Research. 1988. 